\title{
Acercamiento a las partículas adversativas medievales
}

Mónica Castillo Lluch

\section{Citer ce document / Cite this document :}

Castillo Lluch Mónica. Acercamiento a las partículas adversativas medievales. In: Cahiers de linguistique hispanique médiévale. $\mathrm{N}^{\circ} 18-19,1993$. pp. 219-242;

doi : https://doi.org/10.3406/cehm.1993.1088

https://www.persee.fr/doc/cehm_0396-9045_1993_num_18_1_1088

Fichier pdf généré le 12/01/2019 


\section{ACERCAMIENTO \\ A LAS PARTÍCULAS ADVERSATIVAS MEDIEVALES}

\section{Introducción}

Todos los manuales de historia de la lengua nos recuerdan que el esfuerzo literario de Alfonso X capacitó al castellano como lengua apropiada para la exposición didáctica y, en general, como instrumento de cultura. Así, el castellano, paso a paso, iba definiendo su gramática y su léxico al tenerse que acomodar a la exposición escrita $y$, a su vez, ganaba el prestigio de ser una lengua no exclusivamente de comunicación oral, como había sido hasta entonces, sino con funciones de lengua de cultura. También sabemos que en esta labor fue decisiva la agilización de la sintaxis por medio de la introducción de nexos conjuntivos que dan mayor lógica y trabazón al periodo largo de la prosa medieval. Sin embargo, pocas veces advertimos que, si bien en la prosa del Rey Sabio nos encontramos con conjunciones de idéntica forma fonética a las del castellano actual, éstas tienen valores sintácticos y contextos alejados de los que poseen nuestros nexos modernos. Veamos como ejemplo la siguiente oración:

E en esse anno metio Izid rey de los alaraues so el su sennorio et su secta todas las tierras que en derredor dell eran, pero a plazer de los que y morauan, cal amauan mucho por que numqua quiso seer muy loçano ni esquiuo contra ellos pero que era rey, mas manteniesse con ellos comunalmiente bien como otro omne su ciudadano. (299b16)

El objeto del presente trabajo es el de mostrar un corpus de ejemplos encontrados en la Primera Crónica General en los que se reflejan 
los distintos valores que tenían ciertas conjunciones adversativas en la época medieval. Asimismo, estudiaré sus contextos, su frecuencia, sus sentidos desplazados en relación a los nuestros, ciertas expresiones desaparecidas con valores adversativos, etc. Para esto, en algunas ocasiones me apoyaré en el juicio de los gramáticos y lexicógrafos, pero en otras, criticaré sus teorías, que no son enteramente válidas, sobre todo dentro del ámbito sintáctico, como veremos a lo largo de estas páginas.

Las obras a las que he acudido para conocer la historia y usos de los nexos adversativos estudiados son el Diccionario de Autoridades de la RAE, el DCECH y el DECLLC de Corominas, la Gramática española de Alcina y Blecua, el Diccionario de dudas y dificultades de la lengua española de M. Seco, el Curso Superior de Sintaxis española de Gili Gaya, el Esbozo de la RAE - del que tomo gran parte de terminología - y los estudios de José Muñoz Garrigós ${ }^{1}$, y de J. Vallejo ${ }^{2}$, únicos acercamientos específicos, estos dos últimos, a los nexos adversativos desde una perspectiva diacrónica.

Los ejemplos los he extraído de tres bloques de capítulos a lo largo de la Primera Crónica General: el primer conjunto de capítulos estudiados corresponde a las primeras quince páginas de la obra; el segundo extracto de capítulos es el que Alfonso $\mathbf{X}$ dedica a la narración del reinado del rey Bamba, situado en la mitad de la obra y, para acabar, de entre los últimos capítulos del libro he seleccionado los del encuentro del Cid con sus hijas y esposa después de conquistar Valencia, las bodas con los infantes de Carrión y la afrenta de Corpes.

En primer lugar, considero interesante exponer el índice de frecuencias de los nexos que he encontrado a lo largo de la obra:

\begin{tabular}{|l|c|c|c|c|c|c|}
\hline & MAS & MAS (sino) & MAS PERO & PERO & PERO QUE & SINON \\
\cline { 2 - 7 } d. I & 13 & 2 & 1 & 3 & & 5 \\
d. II & 18 & 6 & 7 & 8 & 8 & 3 \\
d. III & 20 & 3 & & 3 & 1 & 3 \\
\cline { 2 - 7 } Total & 51 & 11 & 8 & 14 & 9 & 7 \\
\hline
\end{tabular}

1) J. Muñoz Garrigos, "Sobre el origen de los nexos adversativos en español», Cahiers de Linguistique Hispanique Médiévale, 6, 1981, pp. 41-56.

2) J. Vallejo, "Sobre un aspecto estilístico de don Juan Manuel", Homenaje a Menéndez Pidal, II, 1925, pp. 63-85. 
En la tabla anterior podemos observar que son anormales las distintas frecuencias de MAS PERO y de PERO QUE en los diferentes bloques comparados.

En efecto, en la obra de Alfonso existen desigualdades, por un lado cronológicas y por otro ocasionadas por los distintos redactores, que dan lugar, entre otras particularidades, a diferencias en los usos y frecuencias de los nexos conjuntivos aquí estudiados. Estas disparidades las recoge Vallejo en su estudio del siguiente modo:

\begin{tabular}{|c|c|c|c|c|c|}
\hline $\begin{array}{l}\text { PARTE } \\
\text { MÁS } \\
\text { ARCAICA } \\
\text { c. } 108\end{array}$ & \multicolumn{2}{|c|}{ DE ALFONSO $x$} & \multicolumn{2}{|c|}{ DE SANCHO IV } & $\begin{array}{c}\text { ESTILO } \\
\text { DIFERENTE } \\
\text { cap. } 1135\end{array}$ \\
\hline \multirow[t]{2}{*}{$\begin{array}{l}\text { pero que } \\
\text { no ante } \\
\text { no mas pero } \\
\text { c. } 108\end{array}$} & $\begin{array}{l}\text { no pero que } \\
\text { ante } \\
\text { no mas pero } \\
\text { cap. } 385\end{array}$ & $\begin{array}{l}\text { pero que } \\
\text { mas pero } \\
\text { no ante } \\
\text { cap. } 794\end{array}$ & $\begin{array}{l}\text { mas pero } \\
\text { cap. } 900\end{array}$ & no mas pero & $\begin{array}{l}\text { maguer(ar) } \\
\text { mas pero } \\
\text { pero = «tamen» } \\
\text { cap. } 1135\end{array}$ \\
\hline & $H^{a}$ romana & $\begin{array}{l}\text { Godos, Ast., } \\
\text { F. Gonz., } \\
\text { Inf. Lara, } \\
\text { I. Garcia }\end{array}$ & \multicolumn{2}{|c|}{$\begin{array}{l}\text { Fern. I, Zamora, } \\
\text { Alfo VI, Cid, } \\
\text { Toma de Valencia }\end{array}$} & $\begin{array}{l}\text { Alf }{ }^{\circ} \text { VIII } \\
\text { Fdo III }\end{array}$ \\
\hline
\end{tabular}

(VAllejo, p. 79)

\section{MAS}

\subsection{Definición y valores}

Deriva de MAGIS, utilizada ya como conjunción adversativa desde el latín vulgar. Según juicio de Joan Corominas, "primitivamente servía para agregar una circunstancia nueva, con el valor de 'hay más' 'es más' y después pasó a emplearse como hecho alegado en oposición a lo anterior». Éste recoge asimismo en su artículo la tesis de Bourciez, según el cual, MAGIS se encuentra también en Virgilio, Catulo y otros autores con el sentido de 'más bien' (= potius). Corominas acaba afirmando que «es posible que éste, solo o en combinación con el otro, sea el verdadero origen de la acepción adversativa». 
Pocos son los datos que encontramos acerca de los usos antiguos de esta conjunción en la bibliografía consultada. Los gramáticos se limitan a señalar que su uso es equivalente al de PERO o SINO, y que sólo la encontramos hoy raramente y con valor marcadamente literario o arcaico.

En la lengua antigua era la conjunción adversativa por excelencią y hasta bien pasado el periodo clásico no fue desbancada por PERO. En su uso medieval, según se desprende del análisis de los ejemplos que hemos recogido, MAS tenía matices semánticos y aparecía en contextos que escapan a la intuición lingüística moderna.

El Esbozo señala que en textos antiguos aparece a veces con el significado de SINO, acepción que ha conservado hasta hace poco en el padrenuestro: «No nos dejes caer en la tentación, mas líbranos del mal».

Aparte de estos valores restrictivo y exclusivo de MAS - en terminología de la Academia -, ninguno de los estudios lingüísticos consultados contempla otros usos antiguos de la conjunción, excepto el de Muñoz Garrigós, quien en su artículo añade a los dos valores anteriores el de adversativa debilitada. Su clasificación de los usos de MAS es la que adoptaremos aquí, a falta de una descripción más acertada de los matices gramaticales, y en particular semántico-pragmáticos de esta partícula ${ }^{3}$.

\subsection{Ejemplos}

\section{2.a. Valor adversativo debilitado}

Este valor lo presenta MAS en inicial de frase normalmente, donde su carácter adversativo aparece atenuado y, más que una conjunción adversativa, parece un simple signo de separación.

(1) uinieron los thiracianos e poblaron una tierra a que pusieron nombre Thiracia; mas los que uinieron despues encortaron le el nombre e dixieron le Tracia. (6a32)

3) Como afirmábamos anteriormente, hay matices y contextos de mas que escapan a la intuición moderna (véase ej. 4a), y estos no los recoge Muñoz Garrigós en su estudio. Posiblemente haya una explicación pragmática que dé cuenta de dichos contextos, pero los límites del presente trabajo nos impiden contrastar un número suficiente de datos para explicar el problema. 
(2) El rey quando lo oyo, caualgo a grand priessa con grand companna cuedandol y prender ante que fuxiesse; mas el duc estando en una uilla a que dizen Asperiana, quando lo oyo dezir que el rey Bamba se tornara de Nems e yua sobrel, tan grand fue el pauor que ouo que non oso y dar otro conseio, si non que penso de foyr ... (293b2)

(3) e corrieron la tierra e fizieron grand danno et gran mortandad en ella; mas luego que lo sopo el buen rey Bamba enuio alla corriendo su hueste ... (300a15)

(4a) et yo las caso, mas uos non (601b5)

En la frase anterior MAS puede ser interpretado de distintas maneras. La razón de su inclusión en el presente epígrafe responde al hecho de que la misma frase desprendida de la conjunción MAS guarda un valor adversativo que, de tan obvio pragmáticamente, provoca que la frase sostenga todo su sentido sin la partícula. Por tanto, la aparición de MAS resulta redundante, enfática, no introduciría por sí misma la adversación, sino que la subrayaría. También se puede postular para este ejemplo un valor adversativo exclusivo. Si invertimos linealmente el orden de la oración obtendríamos: «non uos, mas yo las caso», estructura sintáctica completamente regular, introducida por la negación, elemento indispensable en toda adversación exclusiva. De hecho, y como razón adicional para apoyar la argumentación anterior, se podría alegar que en español actual - en el que la estructura de (4a) ha desaparecido -, se utilizaría en el mismo contexto una fórmula adversativa exclusiva: «no eres tú el que las casa, sino yo". Aún así este ejemplo resulta uno de los más conflictivos, y su dificultad de interpretación aumenta cuando constatamos que es posible encontrar el mismo tipo de enunciado sin utilizar MAS. En (4b) tenemos un que universal que tendría un valor claramente adversativo-enfático, recogido por la RAE y Gili Gaya ${ }^{4}$ :

(4b) et el rey, alla do esta, las casa, que yo non. (602a30)

4) RAE, Esbozo, § 3.18.8. S. GILI GAYA, Curso Superior de Sinıaxis española, Barcelona, Biblograf, 1990, § 215. 
A mi parecer, de modo bastante evidente en el siguiente párrafo, el segundo MAS no tiene valor adversativo ninguno. Creo que igual que se ha criticado tradicionalmente el abuso en la utilización de ET en ciertos pasajes de la obra de Alfonso X, del mismo modo, en ocasiones, podemos hablar de un exceso en el uso de MAS:

(5) faziendo mucha onrra et muy grant algo a los infantes de Carrion, sus yernos, que tenie en lugar de fiios; mas ellos falardonarongelo mal, el non lo meresciendo. Mas ellos fizieron a guysa de malos ... (607a25)

En los siguientes casos tampoco veo un claro valor adversativo de MAS, del que se sigue "abusando»:

(6) Por estas razones que el rey dixo, los caualleros le besaron las manos et touierongelo por grant merçed, et fincaron en la corte del rey don Alfonso fasta que el Çid fue vengado. Mas agora dexa la estoria de fablar dellos, et torna a contar en Ordonno et en las duennas que fincaron en el robredo de Corpes. (610b28)

(7) Paulo [... ] fuxo de Narbona, ca non oso y esperar la uenida del rey, e dexo en Narbona a Victimiro [...] y otrossi a Ramiro el falso obispo, et a Argemundo el Gultricion, que era su alfierez. Mas Ramiro quando uio la hueste del rey, cuydosse guarir fuyendo ante que lidiassen la uilla, et salio fuera, et fuxo; mas luego fue preso en termino de Beders, et troxieron le al rey. (287b20)

\section{2.b. Valor adversativo restrictivo}

Es su valor más frecuente en español medieval, hasta cierto punto equivalente al que posee la conjunción adversativa restrictiva PERO actual.

(1) y este fizo grandes fechos e buenos, mas no son contados en estorias ... (7b6)

(2) el dixo que cibdat aurie alli muy grand, mas otro la poblarie, ca non el; (8b26)

(3) E por esto era muy mal quisto de todas las gentes, mas no osauan yr contra el por que no auie y qui los deffender; (9b28)

(4) e por end ouo con ella su acuerdo de poblar Caliz. Mas era logar muy perigloso ... (11b3) 
(5) El rey finco entonces con los mas pocos, et yua se empos aquellos que se fueran por Ausona; mas el diablo, que es enemigo de todo bien et siempre punna que en las buenas obras meta su mala semient, mouio a unos de la huest ... (286b22)

(6) e estauan muy bien guarnidos de gran beldat darmas, mas mucho mas de nobleza de coraçones. (288b31)

(7) Et de la otra parte auye muy grant pesar por Aluar Saluadorez que fincaua alla preso; mas fiaua en Dios que quando otro dia viniesse, que el lo sacarie de poder de los moros. (597a24)

(8) et bien uos digo que de mi grado yo non querria este casamiento; mas pues que el rey nos lo conseia . . . (600a24)

(9) Et luego otro dia, fablo con donna Ximena en razon del casamiento de sus fijas, et quando lo ella oyo, mostro quel non plazie; mas pues que el rey fablaua en esto, dixo que era bien. (600a30)

(10) Desi tollieron las cinchas a las siellas, et firieronlas con ellas de muy grandes feridas; et ellas dando muy grandes bozes et llorando muy de rezio et acomendandose a Dios et a Sancta Maria que les ouiessen merçed. Mas quanto ellas mas bozes dauan et mas llorauan, tanto ellos cada uegada mas crudos eran en mal fazer ... (609a18)

\section{2.c. Valor adversativo exclusivo}

Tanto en el interior de frase como al comienzo de la misma, es frecuente el valor adversativo exclusivo (= SINO) de MAS. En este caso, el primer elemento oracional lleva negación (exigida por la semántica de SINO).

En el siguiente ejemplo, MAS tiene un valor específico de SINO, el equivalente a 'solamente', 'tan sólo', 'nada más que' (como en una oración del tipo «no te pido sino que me escuches con paciencia») 5 :

(1) [Pero Bermúdez, muy nervioso, se lamenta de no haber evitado la afrenta de Corpes e incita al Cid a vengarse cuanto antes de los falsos de Carrión :] Et non se que uos diga, mas tengome por mal andante porque uos non uengue ... (614a20)

5) Véase la clasificación de los valores de sino del Diccionario de Autoridades recogida más abajo. 
(2) Hercules enuio dezir a Gerion que las yentes no auien por que matarse ni por que lazrar, mas que lidiassen ellos amos un por otro. (9b46)

(3) Dios lo sabe que yo non digo esto por uos espantar, mas por que me pesa de uuestro mal ... (289a24)

(4) ca en uerdad nol preciauan nada a el nin a los que con el uinieran de Espanna; mas, lo que peor era, tenien los en desden . . . (290b2)

(5) e tan bien yuan ordenados et tan apuestamientre que ninguno non salie dell az, mas cada uno tenie muy bien so logar; (291b25)

(6) e esto non lo fazie por cobdicia que ouiesse de tomarlos nin de auerlos, mas por fazer dellos reuerencia et onrra a los sanctos . . (292b7)

(7) dixo que non ouiesse miedo, ca todo mensaiero de su sennor non deue auer verguenna nin miedo, mas recabdar lo que su sennor manda ... (605a3)

(8) et non tan solamiente los cristianos, mas todos los moros que eran siruientes del Çid fazien grant duelo ... (614b24)

En la actualidad, en español resulta imposible hallar SINO (aquí MAS con valor exclusivo) con oraciones en imperativo. Al parecer, como se desprende de la oración que sigue, en castellano antiguo era perfectamente conveniente este contexto. El estudio de estas posibles distribuciones sintácticas, perdidas en la lengua actual, se revela enormemente interesante:

(9) Non lloredes, ca non uos cae bien, mas callatuos et dat a entender que non dades nada por ello. (604a 19) 


\section{MAS PERO}

\subsection{Definición}

El caso de MAS PERO plantea un problema de carácter teórico. S. C. Dik, en su obra sobre la coordinación ${ }^{6}$, enuncia la siguiente tesis formal: «two members can never be coordinated by more than one coordinator». Esta regla da cuenta, por ejemplo, de la imposibilidad de encontrar en castellano actual Y y PERO como compuesto. Tanto la ocurrencia de ET PERO (que veremos en páginas más abajo) como la de MAS PERO constituirían, pues, un contraejemplo a la argumentación de este autor, considerando que en ambos casos tenemos asociados dos coordinadores.

Ahora bien, llegados a este punto, es necesario establecer una distinción entre dos tipos distintos de partículas coordinantes por su naturaleza sintáctica: conjunciones y adverbios. Echaide, en su estudio sincrónico sobre la adversación en español ${ }^{7}$, basándose en la teoría de Dik y haciendo referencia a la imposibilidad de combinación de dos coordinadores, opina que "es interesante tener en cuenta este criterio para establecer la distinción entre conjunciones coordinantes y partículas o locuciones adverbiales, que a veces pueden acumularse a la conjunción».

Por consiguiente, en la descripción sintáctica del compuesto MAS PERO (y ET PERO) cabe otra hipótesis distinta a la que postula que ambas son conjunciones coordinantes, y que, por tanto, respetaría la teoría de Dik. Seguramente, en la lengua antigua uno de los dos conectores no fuera una verdadera conjunción, sino que, posiblemente, en la conciencia de los hablantes medievales e incluso clásicos, PERO se comportara como adverbio, estuviera en un momento de transición entre la categoría de adverbio y la de conjunción o bien disfrutara de ambas categorías ${ }^{8}$.

6) S. C. DiK, Coordination: its implications for the theory of general linguistics, Amsterdam, North-Holland, 1968, p. 34.

7) ANA MARIa ECHAIDE, «La coordinación adversativa en español: Aspecto sincrónico», Revista de Filologia española, LVII, Madrid, CSIC, 1974-1975, pp. 1-33. Para la cita: nota 2, p. 3.

8) En este sentido, sólo en Seco se encuentra un análisis diacrónico acertado del carácter sintáctico de pero:

Pero, adverbio en el interior de oración - no al principio -, como equivalente de sin embargo, se usó en la época clásica: «Os la pusiera en vuestras 
Este fenómeno vendría corroborado también por la posibilidad de encontrar en determinados documentos PERO en medio del miembro adversativo, no necesariamente encabezándolo - esta posición la veremos más adelante, en el capítulo dedicado a PERO -. Tendríamos así un caso parecido al del actual pues ${ }^{9}$, que en su versión de conjunción es palabra átona y sólo va al comienzo de la proposición, y como adverbio es palabra tónica y puede ir intercalado en la frase o al final de ella (con separación del resto de elementos por pausa fónica, representada ortográficamente por medio de comas).

En relación con este análisis, sería interesante estudiar las distintas acentuaciones sincrónicas de PERO, incluso regionales - en el habla de Bilbao lleva la fuerza tónica en la o cuando va pospuesto o solo, esto es, cuando es adverbio - o de otras lenguas - clarísimamente en el catalán tenemos un PERO conjunción y otro adverbio; en Italia y en el judeoespañol de Marruecos se conserva también la acentuación aguda etimológica $-{ }^{10}$, etc.

Como última prueba para apoyar este argumento aduciremos que, al parecer, en el romance medieval era posible encontrar PERO con un valor de SIN EMBARGO, tras frases concesivas. Esto es, era conveniente algo como «aunque Juan suspendió, pero no lo castigaron", oración sólo posible actualmente con un adverbio como sin embargo («sin embargo no lo castigaron»). Vallejo se acerca a este uso cn su artículo:

Pero, empleado como tamen tras una frase concesiva, a juzgar por la Crónica general (hasta el cap. 965), era ya un arcaísmo, al que

manos para que hiciérades della a toda vuestra voluntad y talante, guardando, pero, las leyes de la caballería» (CERvantes, Quijote, I, 550) (op. cit., p. 288).

El resto de autores no nos habla de la categoría de pero en estos contextos. Alcina y Blecua, presentan un epígrafe en el que se recogen estos usos adverbiales de pero bajo el título de «Posición de la conjunción». Asimismo, Muñoz Garrigós, en su artículo citado, p. 42, interpreta la ocurrencia del compuesto mas pero como contrargumento a la tesis de Dik sin considerar la posibilidad de que pueda tratarse de dos coordinadores distintos. Afirma que el postulado de Dik tiene un «no despreciable margen de error cuando hay que referirlo a la lengua medieval española» y aporta un ejemplo de mas pero extraído de la Primera Crónica General.

9) Para el caso de pues véase el artículo de Jose Portoles, «El conector argumentativo pues», Dicenda, 8, Madrid, 1989, pp. 117-133.

10) Para estas pronunciaciones véase el Esbozo, p. 72, nota 22. 
habían sustituido con todo eso, por todo (eso), etc. En la Crónica se usa muy poco. [Después hubo una influencia de los trabajos literarios de la corte y los escritores de final de siglo recuperan expresiones que se habían perdido, entre ellas PERO = TAMEN] Así aparece con mucha frecuencia en la parte más moderna de la Crónica (desde el cap. 965), y así pasó al siglo XIV, prolongándose su uso en los escritores cultos por otros siglos más. (Vallejo, p. 75)

La determinación de la categoría a la que pertenece el PERO antiguo merece, no obstante, un estudio más profundo que no tiene cabida en el presente trabajo, en el que me limito a apuntar una hipótesis.

Según señala Muñoz Garrigós, PERO viene a reforzar el valor de MAS, que se encontraba muy debilitado. Observemos que en los siguientes ejemplos, efectivamente y como era de esperar, el compuesto tiene un carácter adversativo más enérgico que el de las respectivas partículas que lo integran cuando figuran por separado.

\subsection{Ejemplos}

(1) Cuenta la historia que quando a este rey Bamba quisieron alçar rey, que lo non quiso el consentir de seerlo; mas pero al cabo ouo de otorgar lo con miedo et menazas quel fizieron, pero mando ell et deffendio quel ninguno nol llamasse rey fasta que recebiesse el sagramiento de la uncion ... (284a3)

(2) et firien se unos a otros de dardos e de saetas, e fue muy grand aquella lid por todos lo auien a coraçon de se matar; mas pero de la parte del rey tan espessas yuan las piedras et las saetas, que non semeiauan al si non el granizo muy espesso quando cae en tiempo de uerano. (288a11)

(3) La uida uos otorgo agora; mas pero mando que uos guarden en prision muy bien fasta que seades iudgados ... (292a28)

(4) E por uentura esfuerça se Paulo et cueda auer ayuda de franceses; mas pero esto es sabido llanamientre, que quando los franceses fueron muchas uezes coytados [...] que demandaron ell ayuda de los godos ... (286a4)

(5) nos non la merescemos; mas pero la tu fuerça et el tu poder non deue complir se fasta en cabo, et la tu espada non cumpla la uengança ... (291a44) 


\section{PERO}

\subsection{Definicion y valores}

Corominas apunta que PERo nos llega del nexo consecutivo del latín postclásico PER HOC 'por esto', 'por tanto', valor que conservaba todavía en el latín medieval peninsular y que incluso se documenta, aunque muy raras veces, en el español medieval (Berceo). Más tarde, empleado en frases negativas, tomó el sentido adversativo de 'sin embargo', conservado en la Edad Media, posteriormente atenuado hasta hacerse equivalente de MAS. De nuevo aquí tendríamos una pista más para apoyar la argumentación anterior en favor de la posible categoría adverbial de PERO. Se documenta por primera vez en Berceo.

Su acentuación etimológica sobre la última sílaba, que se mantiene en catalán e italiano, se abandona en castellano por su posición proclítica. Frente al portugués, en castellano invadió el campo de uso de MAS hasta prácticamente eliminarlo, pero como vamos viendo, su uso es aún muy rígido en la Primera Crónica General, donde se prefiere masivamente la utilización del derivado de MAGIS.

Corominas en su artículo etimológico sigue el trabajo de Vallejo para definir los valores antiguos de PERO, que se pueden resumir en los siguientes términos: En el romance primitivo PERO conserva todavía $1^{\circ}$ ) un valor adversativo más fuerte que el de 'mas', muchas veces equivalente a 'sin embargo'; esto es general en lengua de Oc, catalán e italiano, y es frecuente también en castellano, por lo menos hasta el siglo XIV; en este idioma tiende, sin embargo, a adquirir otros valores: $2^{\circ}$ ) a veces es ya equivalente de mas, y $3^{\circ}$ ) sobre todo es muy frecuente el empleo con el valor de 'aunque': "los males de los dados dize maestro Roldán / . . / más alholís rematan, PERO no comen pan, / que corderos la Pasqua ni ansarones San Juan» (Juan Ruiz 556c), «si las mançanas sienpre oviesen tal sabor / de dentro, qual de fuera dan vista e color, / non avrié de las plantas, fructa de tal valor; / mas ante pudren que otra, PERO dan buen olor" (Juan Ruiz, 163d). Con este valor concesivo es más frecuente la combinación PERO QUE, como veremos más adelante.

El gran problema histórico que se plantean los lingüistas reside en la difícil explicación de la desaparición de MAS y el auge de PERO. Parece haber dos comportamientos lingüísticos distintos en lo refe- 
rente al uso de PERo en la península. Pronto PERo tendió a reemplazar a MAS en su valor de adversativa atenuada, como conjunción de uso oral en la zona de Castilla y Cataluña, frente a la preferencia occidental (leonesa y portuguesa) por el empleo absoluto de MAS (MAIS que conserva hasta ahora nuestra lengua vecina). Así el leonés medieval se opuso a la innovación del Centro y Oriente ibéricos en el uso de PERO, pues no aparece en el Fuero Juzgo. No obstante, estos datos, recogidos por Vallejo, deben ser matizados, puesto que se encuentran documentos legales de impensable vinculación con el occidente peninsular que carecen también de PERO.

En relación con este problema de aclaración del auge de PERO y pérdida de MAS, hemos encontrado explicaciones contradictorias en Vallejo y en Muñoz Garrigós. Mientras aquél afirma que PERO en la época de Alfonso $\mathrm{X}$ todavía no se había impuesto a mas alegando los siguientes argumentos:

Pero tratándose del español, es muy de notar que el lenguaje de la mayor parte de la Crónica general de Alfonso X, la que se supone escrita por redactores nacidos en la primera mitad del siglo XIII, nos inclina a afirmar que hacia esa época pero no había alcanzado aún - desterrando a mas - el puesto de instrumento adversativo de la lengua usual, ya que su empleo en vez de natural, espontáneo y rico se presenta con extraordinaria rigidez, y como respondiendo a normas de expresión arcaica y a formulismos estilísticos mejor que a funciones propias de un instrumento gramatical en plena vitalidad. (Vallejo, p. 73).

José Muñoz Garrigós hace una interpretación distinta del fenómeno, y apoya - basándose en otro juicio de Vallejo - :

la vinculación de PERO con la lengua oral, con independencia de la debilidad estructural y de contenido que afectaba a MAS. Estaríamos, pues, ante un problema de niveles de lengua: así, mientras MAS seguía su línea histórica de carácter eminentemente literario, PERO, procedente de un nivel inferior, se introduce en la prosa de Alfonso $X$ en virtud de ese carácter integrador de tendencias, a veces tan distintas, que tiene en sus orígenes la prosa castellana. (Muñoz, p. 51)

Por los datos que en el presente trabajo estamos manejando, podemos afirmar que la utilización de la partícula adversativa PERO, 
todavía en el siglo XIII, y en particular en el marco de la Primera Crónica General, no disfruta de toda la sol tura que adquiriría posteriormente. De esto dan fe las frecuencias de aparición recogidas en páginas anteriores, en las que queda reflejado que en aquel momento aún se prefería el uso MAS como adversativa principal.

\subsection{Posicion}

Siguiendo a Corominas, es propia del castellano la colocación de PERO al principio de la frase, frente a los romances más orientales, que admiten o prefieren la posición detrás de los primeros miembros de la frase (y recordemos que en esta distribución sintáctica PERO es adverbio); esta última construcción no es enteramente ajena al castellano medieval, pero tal y como apunta Vallejo (pp. 79-80) sólo se cuentan poquísimos ejemplos del siglo XIII, entre los cuales el de la obra que estudiamos aquí:

Bien auenturados fuestes uos a los que Mitridates [. . . ] empoçono las fuentes [...] et matouos con las aguas dellas, ca pero auiedes dellas assaz, et non muriestes penados de sed . . (75b50)

Posteriormente, según indicaciones de Vallejo, escritores del último tercio del siglo XIV y primera mitad del XV posponen la partícula a los primeros miembros de la frase adversativa. Este es el caso del Corbacho, que lo hace por imitación italiana (o catalana si seguimos a Corominas): «avaxa los ojos de muy vergonçosa; bien sabe pero qué faze» (161.17). Desde el siglo XVI, la construcción se halla sobre todo en poetas por necesidad métrica y por influjo italiano. Entre otros son representativos los ejemplos de Juan de Valdés, de Garcilaso y del Quijote:

Os la pusiera en vuestras manos para que hiciérades della a toda vuestra voluntad y talante, guardando, pero, las leyes de la caballeria. (Quijote, I, cap. 52)

Así pues, esta construcción se debió sobre todo a influjos extranjeros aunque - siguiendo a Corominas - en algún punto pudo tener arraigo genuino, puesto que sigue oyéndose en Bilbao, donde observa Arriaga que la acentuación "peró» se oye siempre que va pospuesto o solo: «no quiero, peró ... sí, peró ....». 
En la actualidad, y aparte de la variante de Bilbao, la posición de PERO es siempre inicial y en este sentido corrige Seco ciertos errores cometidos por influencias catalanas: ( Hoy sólo se usa [PERO como adverbio intercalado] en el castellano de Cataluña: «Todo, pero, está decidido sólo a medias» (X, Montsalvatge, Vanguardia, 9.5.1978, 62)).

Por otro lado, el catalán PERO guarda su carácter adverbial cuando aparece pospuesto a los primeros elementos de la frase adversativa. Como señala Corominas, al final de la Edad Media perdió el catalán las adversativas MAS o MES, utilizando en su lugar PERO. En el $D E C L L C$ queda recogida esta construcción con PERO intercalado desde una época muy temprana de la lengua catalana:

És antiga, i sempre s'ha tingut per construcció elegant, la intercalació de però dins la frase amb el valor de 'tanmateix, amb tal restricció' que ja trobem en Jaume I: «Féu-nos parlar pleyt - Xuaip - que si Nós - li faíem bé, que ell nos retrie los castells - en tal manera, però, que él pogués honradament viure» 6ag., § 113, p. 163). Molt freqüent en Bernat Metge [...]. Us que sempre continuà vigorós a Mallorca, i ni en el Continent no desaparegué, si bé tornant-s'hi més rar: «Deu-se, però, advertir que ha de ser alguna persona idònea».

Con la llegada de la Renaixença, la lengua literaria recuperó esta construcción - abandonada en gran parte de los países catalanes con mucha naturalidad, consiguiendo un éxito total; si bien todavía escaseó un tiempo entre los prosistas del Continente, Verdaguer ya lo utiliza. Y, por fin, siguieron con este uso escritores de todas las tendencias: Prat de la Riba, Coromines, Rovira Virgili, e incluso Maragall y Narcís Oller: «la qüestió, però, era anar allunyant, aplassant, l'espetec", La Febre d'Or (1982, III, p. 114).

Acaba su artículo Corominas señalando que en el siglo $\mathrm{XX}$ el catalán conserva esta construcción "como una doble conquista», aceptada generalmente y de uso corriente en la lengua literaria tanto del Continente como del resto de las Islas (donde también se usa en posición final de frase: «jo no us hi podria acompanyar, perd»). 


\subsection{Ejemplos}

\section{3.a. Uso adversativo más fuerte que el de MAS}

En (1) aparecen juntos en la misma frase MAS y PERO, lo cual permite una comparación en el mismo contexto de las dos partículas. En mi opinión, PERO aquí tiene un valor adversativo más reforzado que el de MAS:

(1) Paulo subio entonces en una torre por asmar et compassar la huest; mas quando uio la caualleria del rey, crebol el coraçon, pero començo de dezir assi ... (289b11)

(2) El rey quando esto uio puso de entrar en tierra de Francia et alla lo auer con ellos, pero ouo despues su conseio et dexosse daquesto et non quiso crebantar los pleytos nin las treguas que el rey de Francia auie puestas con los godos. (293a35)

En (3) nos encontramos juntos a ET y a PERO, lo que evidencia de nuevo el carácter adverbial de PERO, que posee un valor muy acusado, equivalente a 'pero sin embargo, con esto':

(3) Cada vno en su guysa fueron muy buenos aquel dia et sobre todos el Çid Canpeador commo maior et meior. Et pero con todo esto, atant grant era el poder de los moros, que los non podien arrancar; et duro la fazienda bien fasta ora de nona. (606a45)

(4) E pusieron le assi nombre unas gentes que la poblaron a que llamauan lusios; pero algunos cuentan que este nombre ouo por trebeios que mando y fazer Hercules ... (6b53)

(5) [dice el mensajero del rey Búcar :] sennor Cid Canpeador, el rey Bucar de Marruecos, mi sennor me enbia a ti, et dizete quel tienes grant tuerto en tener Valencia que fue de sus auuelos, et que desbarateste al rey Iunes su hermano; et agora es uenido con XXIX reyes por vengar a su hermano, et por conbrar Valencia pesando a ti et a quantos christianos son contigo. Pero, con todo esto, dixome que porque el oyo dezir que tu eres omne entendudo et sabio que te quiere fazer tanto quel dexes a Valencia con todo su termino et que te vayas pora Castiella ... (605a8)

[a esto el Cid da la respuesta de que no dejará Valencia y que cuando menos se lo esperen saldrá a luchar con ellos. El mensa- 
jero comunica la decisión del Cid a su rey :] Et quando el esta respuesta dixo, estauan y los XXIX reyes, et mucho fueron marauillados de las palabras que el Cid dixiera; pero bien cuydauan que tan ayna non saldrie a la batalla, et començaron ordenar commo yrien cercar a Valencia. (605a42)

\section{3.b. Introductor de oraciones}

(1) Estos obispados son treze et an de obedecer al arçobispado de Merida; pero ya de suso dixiemos [. . . ] que ell obispado de Edanna et de Viseo que auien a el de obedescer ... (297b25)

\section{3.c. PERO concesivo \\ (PERO QUE más frecuente en la $\mathrm{Cr}$. General)}

En la oración que sigue cabe una interpretación concesiva aunque, desde luego, no es definitiva, y puede ser simplemente adversativa:

(1) Tres Hercules ouo [...] e el primero fue en el tiempo de Moysen, pero nacio ante que el ... (7b3)

\section{3.c.i. Definición de PERO QUE}

Corominas recoge el frecuente empleo de PERO con valor concesivo en la lengua medieval, del que dan muestra los ejemplos que hemos citado más arriba. Con este valor, sin embargo, es más normal la combinación PERO QUE: «entró discordia entr'ellas; e entended que por este lugar de la deessa Discordia, que entró en aquel convite pero que desechada» (General Estoria, RFE XV, 25); y todavía pueden hallarse algunos ejemplos sueltos en el Siglo de Oro: "andaba tan contento, que quisiera de noche no desnudarme y de día no dejar calle por pasear, para que todos me vieran, pero que no me conocieran» (G. de Alfarache, Cl. C. II, 119.6).

Vallejo, aunque reconoce la imposibilidad de fechar el nuevo empleo de PERO QUE o PERO como partícula concesiva, nos habla de los orígenes de esta combinación de PERO y QUE en los siguientes términos:

Es bien conocido el origen de esta partícula concesiva; pero, con su antigua significación "sin embargo», fué empleada para encabezar la construcción concesiva, del mismo modo y con igual sentido que nuestra actual locución a pesar de que. Se usa con 
indicativo, sintaxis que conserva rigurosamente en todos los escritos hasta su desaparición, y que muestra, además, su carácter de instrumento de la lengua hablada. (Vallejo, p. 72) [ . . ]

Creo que pero que representa un elemento de la lengua hablada. De una parte responde a una necesidad natural de crear un instrumento especialmente intensivo para la concesión de lo real, como se crean con igual fin en la hipotética. Su sintaxis con indicativo se mantiene rigurosamente, lo que no caracteriza a las meras partículas literarias que, salvo el caso de rehuir una confusión de sentido [...] se prestan por analogía a otras construcciones. Finalmente pero que aparece en escritos de todas clases (reserva hecha de los legales).

Ya en la primera mitad del siglo XIII su colisión con pero adversativo que se prestaba a ambigüedades y confusiones y que acabó por eliminarlo, restringía extraordinariamente su uso. [. . .] En la Crónica general abunda mucho, con notable diferencia entre algunas de sus partes, según los redactores respectivos. [...] A partir del capítulo 965 se revela muy bien su rápida decadencia. Desde fines del XIII y primer tercio del XIV figura casi siempre encabezando la segunda frase con un sentido oscilante en que se mezclan las expresiones concesivo-restrictiva y adversativa. [cita ejemplos de la Crónica General 520a11, 537b31] (Vallejo, p. 80).

La decadencia de PERO QUE surgió ya en el siglo XIV. Lo conservamos como arcaísmo aún en el XV en Pérez de Guzmán y Santillana.

\section{3.c.ii. Ejemplos}

(1) Los de dentro pero que mucho se alabauan, mas se fiauan en la fortaleza del muro que en la suya et echauan de somo del muro piedras e saetas; e pero que mucho se amparauan bien et lidiauan muy de rezio, mayor danno prendien ellos que non los de fuera ... (289b41)

(2) nin pudo librar otrosi uno de los suyos quel mataran delant, pero que el daua grandes uozes que era suyo, nin ge lo pudo sacar de manos ... (290a48)

De nuevo, a continuación, tenemos una prueba formal de que PERO no es una conjunción exclusivamente, y así nos encontramos 
ante dos coordinadores de distinta categoría, lo cual permite la combinación de E y PERO QUE:

(3) sennor, erramos et pecamos et fiziemos grand nemiga [...]. E pero que tod esto fezimos, la tu grand piedad sea sobre nos et aya de nos merced. (291a33)

(4) aportaron dozientas et setaenta naues de alaraues en tierra de Espanna, pero que non diz en qual logar ... (300a13)

(5) [se prepara una batalla del Cid con el rey Búcar; suben el Cid y los infantes de Carrión a una torre para ver la extensión del ejército moro: el Cid se rie de placer y los infantes están muertos de miedo. Al rato, hacen un comentario los infantes entre ellos de que no quieren entrar en la batalla por miedo a morir, con la desgracia de que uno de los súbditos del Cid lo oye y se lo cuenta a éste :] Et el Çid quando lo oyo, pesol, pero que lo començo a meter en jugleria, et tornosse contra sus yernos et dixoles: «uos, fiios, fincat en Valencia et guardaredes la villa, et nos que somos duchos deste menester yremos en la batalla" (604b24)

(6) Desi murio Tharcus e finco quanto el auie a Rocas; mas pero que auie quant auie mester, no pudo oluidar la cueua, uiniendol emiente la compannia del dragon: (13b45)

III.3.d. PERO DE: valor de 'A PESAR DE'

(1) Oy dezir que el rey Bamba se guisa pora uenir sobre nos con su hueste, e el tu buen entendimiento non se torue por esto, ca bien creo que non puede seer; e pero de mi et del, al que la tu santidad uir uenir con hueste contrall otro, a aquel tenga por sennor et all amor daquel se atenga otrossi. (287a10)

\section{EMPERO}

\subsection{Definición}

En la Crónica General hay escasos ejemplos de este adverbio. En mi lectura sólo lo he encontrado una vez, y sin embargo, como señala Vallejo, es muy usual en las Obras legales, con lo que su carácter de cultismo desde su formación, se manifiesta bien claramente. El mismo autor sospecha que el origen de EMPERO lo encon- 
tramos en una importación culta de un foco influyente. Su etimología se presenta dudosa: tanto Corominas como Vallejo comparten la intriga del origen del prefijo em-, que no saben si deriva de INDE, UNDE, ENDE, IN, o de ET.

Corominas señala que EMPERO es el que ha sustituido en español el empleo pospuesto de PERO. Por otra parte, todos los autores consultados coinciden en afirmar el carácter culto del adverbio, que hoy sólo se utiliza con un marcado carácter arcaico, ni siquiera literario.

\subsection{Ejemplos}

(1) Hercules [...] ouo sabor dir andar por el mundo por las otras tierras e prouar las e prouar los grandes fechos que y fallasse; empero non quiso que fincasse la tierra sin omnes de so linage ... (10b48)

\section{SINO}

\subsection{Definición}

Como tendremos la ocasión de observar, existía a mediados del siglo XIII una total vacilación en la ortografía de la conjunción coordinadora exclusiva - en terminología de la Academia -, vacilación que delata su origen condicional recogido en el siguiente párrafo en palabras de Corominas:

SINO: 'salvo, a excepción de' [sinon, Cid] nació por una elipsis: frases como nadi, sinon dos peones (Cid, 686), son abreviación de si non son dos peones; de ahí pasó luego a conjunción adversativa, indicando contraposición [non se faze assi, sinon..., Cid, 140].

Esta vacilación ortográfica entre SI NO y SINO que puede observar en los siguientes ejemplos, dos frases casi idénticas, separadas por apenas unas cuantas líneas en el texto:

que no la casasse si no con qui ella quisiesse; (11b13)

auie puesto de non casar sino con qui ella quisiesse, (11b29 
En ningún otro sitio como en el Diccionario de Autoridades hallamos una exposición tan detallada de los valores de SINO, y creo que merece la pena reproducirla aquí:

SINO. Particula condicional compuesta de las dos si, y no. En las proposiciones en que se pone alguna condición, tiene la misma significacion que ambas à dos; verbigracia, $S i$ vivieres saldré de casa; y si no vinieres, me quedaré en ella. Lat. Nisi. Sin autem. Si non. Sin minùs.

SINo. Se usa tambien para contraponer los extremos de una oración, como contrarios entre sí, determinando el que se ha de elegir. Lat. Quinimò. Imò potius. CALIST. Y MELIB. f. 57. Hagamosle de señas, que no espere mas, sino que se vaya.

SINO. Se usa assimismo para distinguir una cosa de otra contraponiendolas, y entonces siempre le precede proposición negativa; verbigracia, No es blanco, sino pardo. Lat. Imò. [...]

SINO. Se usa assimismo para exceptuar una cosa de otra, ù entre otras; verbigracia, Nadie entiende esto, sino Fulano. Lat. Praeter. Nisi.

SINO. Con interrogación se usa para arguir à alguno pro el extremo contrario, si fuere cierto, o suponiendole: como Algun delito has hecho; si no por qué huyes?

SINO. Equivale también à demás, ò fuera de, añadiendo extremos à la oración, y siempre es precedido del modo adverbial no solo; verbigracia, No solo por rico, sino por prudente, sabio, \&c. Lat. Sed etiam. Necnon.

SINO. Muchas veces equivale à los adverbios solo, ù solamente, precedido de proposicion negativa; verbigracia, No espero, sino que te vayas, vale tanto como solo espero que te vayas. Lat. Nihil, nisi, vel. prater.

sino. Equivale muchas veces a los modos adverbiales de otra manera, ù de otra suerte, contraponiendo los extremos, y usado con interrogación. verbigracia, Si no, como conseguirás el empleo? Lat. Aliter. Alioqui.

\subsection{Ejemplos}

En los ejemplos siguientes queda constancia ortográfica de la confusión que existía entre la conjunción coordinadora exclusiva y la condicional negativa, origen de la anterior. Obsérvese cómo en 
varias de las construcciones siguientes se trasluce el origen condicional de SINO:

(1) E no finco rio en toda Espanna ques no secasse, sino Guadalquivir y Ebro, y estos corrien muy poco; (14a4)

(2) Del segundo anno fastal quarto del regnado del rey Bamba non fallamos ninguna cosa que de contar sea que a la estoria pertenesca, si non tanto que en el tercero ayunto Moabia rey de los alaraues ... (294b31)

(3) ca ellos son grant gente et non los podriemos arrancar si non con muy grant maestria de guerra. (597a38)

(4) non lo gradesco a omne del mundo sinon a mi Sennor Jesu Cristo. (605a31)

(5) Et esto non lo vio ninguno, sinon vn escudero del Çid ... (606a12)

\section{2.a. ANTE con valor de SINO}

Como se puede ver en las tablas de Vallejo expuestas más arriba, el castellano antiguo utilizó la partícula ANTE como conjunción adversativa exclusiva (equivalente a SINO), aunque su uso pronto quedó anticuado, como lo muestra el hecho de que a partir del capítulo 385 de la Primera Crónica General no se vuelva a documentar.

(1) Ana, que quier dezir en griego tanto cuemo topo, porque ua a logares escondidos so tierra e despues sale, e aquel nombre numqual fue camiado, antel llaman agora Guadiana. (10a10)

\section{Conclusión}

Como se indicaba en la introducción, el propósito de este estudio, era el de hacer una exposición de todos los posibles valores y contextos de las partículas adversativas medievales encontradas en la Primera Crónica General de Alfonso X.

Hemos visto que, en repetidas ocasiones, tanto las connotaciones semánticas, como las distribuciones sintácticas de estas piezas adversativas no se corresponden con las que en el español actual poseen sus herederas etimológicas. Así, se ha hablado del carácter debilitado en términos semánticos de determinada conjunción, de matices 
de sentido propios a un ejemplo en particular, etc. Del lado sintáctico, hay que subrayar la postulación explícita de la hipótesis de la pertenencia del PERO medieval a la categoría de adverbio. Esta nueva formulación, que en principio puede parecer simplemente formal, resuelve cuestiones sintácticas que planteaban problemas de análisis a todos los estudiosos de la cuestión (sobre todo en lo que respecta a la incomprensible existencia de compuestos como MAS PERO y ET PERO, y ciertas posiciones sintácticas de PERO anormales para cualquier conjunción).

Por último, la presentación del corpus de ejemplos pretende ofrecer una visión de conjunto del panorama adversativo en el siglo XIII, fecha emblemática en la formación de nuestro idioma.

Mónica Castillo LluCh, Universidad Autónoma de Madrid, Universidad de París-XIII. 


\section{Bibliografía}

Alcina, J. y Blecua, J. M., Gramática española, Barcelona, Ariel, 1987.

Alfonso X, Primera Crónica General de España, Madrid, Gredos, 1977.

Corominas, J. y Pascual, J. A., Diccionario Critico Etimológico Castellano e Hispánico, Biblioteca Románica Hispánica, Madrid, Gredos, 1981.

Coromines, J., Diccionari etimològic i complementari de la Llengua Catalana, Barcelona, Curial Edicions Catalanes, 1983.

DIK, S. C., Coordination: its implications for the theory of general linguistics, Amsterdam, North-Holland, 1968.

ECHAIDE, A. M., «La coordinación adversativa en español: aspecto sincrónico», $R V E$, LVII, Madrid, 1974, pp. 1-33.

GILI GAYA, S., Curso Superior de Sintaxis española, Barcelona, Biblograf, 1990.

MuÑoz GarRigos, J., "Sobre el origen de los nexos adversativos en español", Cahiers de Linguistique Hispanique Médiévale, 6, 1981, pp. 41-56.

PorTolés, J., «El conector argumentativo pues», Dicenda, 8, Madrid, 1984, pp. 117-133.

RAE, Diccionario de Autoridades, Biblioteca Románica Hispánica, Madrid, Gredos, 1976.

RAE, Esbozo de una nueva gramática de la lengua española, Espasa Calpe, Madrid, 1989.

SeCo, M., Diccionario de dudas y dificultades de la lengua española, Espasa Calpe, Madrid, 1989.

VAllejo, J., "Sobre un aspecto estilístico en don Juan Manuel», Homenaje a Menéndez Pidal, II, 1925, pp. 63-85. 